Fikrah: Jurnal Ilmu Aqidah dan Studi Keagamaan

issn 2354-6174 eissn 2476-9649

Tersedia online di: journal.iainkudus.ac.id/index.php/fikrah

Volume 8 Nomor $12020,(1-24)$

DOI: 10.21043/fikrah.v8i1.7215

\title{
Integrasi Paham Agama: Membangun Kesamaan untuk Menegasikan Perbedaan Telaah Serat Sastra Gending
}

\author{
Muhammad Irfan Riyadi \\ Institut Agama Islam Negeri Ponorogo
}

\begin{abstract}
Abstrak
Islamisasi di Mataram menunjukkan gejala transformasi sistem budaya masyarakat, dari budaya global ke lokal, dari great culture menuju little culture; Sultan Agung murid terakhir Sunan Kalijaga, memainkan peranan penting dalam tugas itu, ia mengkritik keras model Islamisasi yang tidak membangun local conciusness karena mencerabut akar budaya masyarakat dari tempatnya tumbuh, yang menurutnya akan menghambat proses Islamisasi dan proses pendewasaan masyarakat. Maka diciptakannya puisi-puisi alegoris dalam naskah Serat Sastra Gending. Tujuan kajian ini adalah upaya penafsiran terhadap Serat Sastra Gending sehingga ditemukan pola integrative akulturatif dalam meramu model islamisasi yang fenomenal di era Mataram. Kajian dengan mengeksplorasi data pustaka, dirangkai dengan memanfaatkan metodologi penelitian sejarah pemikiran, adapun analisis isinya memanfaatkan hermeneutika sosial. Kesimpulan Penelitian ini terdapat dua hal, pertama, Serat Sastra Gending berisi pokok pikiran tentang integrasi yaitu integrasi diri pribadidan; sedangkan yang kedua, menurut Sultan Agung, manusia hendaknya memahami hakekat ajaran agama secara seimbang. Disitulah inti dakwah dengan model penetration pacifique.
\end{abstract}

Kata kunci : harmonisasi, integrase, islamisasi, serat sastra gending 


\begin{abstract}
Islamization in Mataram shows symptoms of transformation of the cultural system of society, from global to local culture, from great culture to little culture; Sultan Agung, the last student of Sunan Kalijaga, played an important role in this task. as the third king of the Mataram, he strongly criticized the Islamization model which did not build local conciusness because it uprooted the cultural roots of the community from where it had grown, which would hinder the process of Islamization and the process of community maturity. For this reason, he formulated his thoughts through allegorical poems in the Sastra Gending Literature text. The purpose of this study is to provide an interpretation of the literary Sastra gending so that an integrative acculturative pattern is found in concocting a phenomenal model of Islamization in the Mataram era. This study was carried out by exploring library data, which will be assembled by utilizing historical research methodology of thought, while analyzing the contents utilizing social hermeneutics. Conclusion This study has 2 things: 1 ) Serat Sastra Gending contains that's about personal self-integration and divine integration; 2) According to Sultan Agung, human should understand the essence of religious teachings in a balanced way, it will make human life harmonious and peaceful, not mutually blaming and toppling each other. That is the point of preaching with the pacifique penetration model.
\end{abstract}

Keywords: harmony, islamization, integration, Sastra-gending

\title{
Pendahuluan
}

Islam sebagai agama samawi, selain mengajarkan aspek hablun minAllah berupa keyakinan dan ritual peribadatan, juga mengajarkan aspek hablun min al-nas aspek hubungan sosial (muamalah basyariah) (Riyadi, 2014). Ajaran yang kedua ini melahirkan pranata sosial dan budaya yang terekspresi dalam kehidupan para pemeluknya, bahkan terbakukan dalam sebuah bangunan budaya (culture building) (Miswanto, 2012). Culture building yang dibangun oleh budaya agama Islam, pada akhirnya menjadi budaya besar (great culture) mengikuti perkembangan globalisasi Islam yang telah menyebar melewati batas-batas antar bangsa (trans nation). Dalam perkembangan dan penyebarannya ke berbagai daerah di luar Arab, great cluture Islam mengalami benturan dengan budaya-budaya lokal (little culture) yang telah eksis dan telah berakar kuat pada suatu daerah (Larasati, 2018; Otta, 2015; Sanusi, 2017). Pada gilirannya persinggungan dua budaya semacam itu dapat menimbulkan pola-pola penyebaran yang disebut dengan penetration, diantaranya inkulturasi (ketika local culture langsung shock dibawah dominasi budaya pendatang), dapat berbentuk akulturasi ketika budaya pendatang dengan budaya lokal saling berpengaruh secara seimbang dan bisa meningkat menjadi sinkretisasi (syn-cretiozeyn) ketika pertentangan antar dua budaya itu menghasilkan perpaduan sampai ke tingkat aqidah (Ahimsaputra, 1995; Runes, 1976). Apabila pertemuan itu menimbulkan 
proses akulturasi maka yang terjadi adalah symbiotic culture atau penetration pacifique; namun apabila justru pertentangan dan konflik maka telah terjadi clash culture atau penetration violente (Daryanto, 2014; Saefullah, 2018).

Penetration pacifique dapat terwujud apabila terpenuhi beberapa syarat yaitu: terdapat tokoh perantara (disseminator) yang kapabel melakukan diseminasi budaya, terdapat ajaran yang mampu membangun konsep symbiotic culture sebagai legal standing maupun konsep spiritual budaya masyarakat, dan ada upaya membangun konsep dalam ranah aplikasi pada aras implementasi (Alexandri \& Zahra, 2017). Nampak ketiga syarat ini terpenuhi dalam kerja budaya disseminasi Sultan Agung di Mataram, dia sendiri merupakan tokoh disseminator, konsepnya dibangun dalam Serat Sastra Gending, sedangkan aplikasinya diwujudkan dalam ragam kebijakan lokal yang mengarah pada simbolik budaya (Kurnialoh, 2015; Purwanto et al., 2018; Zaenudin, 2014). Maka tidak salah bila upaya Islamisasi Sultan Agung telah mewujud sebagai pola penetration pacifique dan penyelamat bagi rakyat Mataram dari libasan budaya global, dan nyata Islamisasi Mataram merupakan proses paling fenomenal dan paling smooth yang tercatat dalam dalam sejarah dakwah Islam di Jawa (Sungaidi, 2019). Disebut demikian karena proses Islamisasi pada berbagai tempat yang tidak memanfaatkan pola integrasi telah menimbulkan berbagai konflik. Sebagaimana terjadi di Aceh zaman pergantian dari Sultan Iskandar Muda ke Iskandar Tsani, dimana Syeh Hamzah Fansuri, Syamsuddin Sumatrani dan Abdurrouf Sinkili di satu sisi yang mendakwahkan Islam tasawuf Syatatariah, ternyata ditentang hebat oleh ulama pendatang dari India (Pakistan, kini) Nuruddin Ar-Raniri dengan semangat syariahnya, sehingga diperoleh satu keputusan hukum untuk membakar seluruh buku yang mengandung ajaran mistik Wahdat al-Wujud karya Hamzah Fansuri dan menghukum bunuh masyarakat yang tidak mau bertobat dari ajaran itu (Sangidu, 2008); kasus di India juga masyhur telah terjadi dimana konflik Islam-Hindu berlangsung sangat lama dan memakan korban sangat banyak, hingga datanglah Sultan Syah Alam Akbar yang mengajarkan integrasi dan akulturasi agama dalam bukunya Akbar Namah dengan ajaran yang dikenal luas dengan Din-I-Ilahi (Kausar, 2006; Khan \& Sen, 2009; Sokah, 1994). Kedua peristiwa besar di atas terjadi dalam kurun hampir sama yaitu akhir abad 16 dan awal abad 17 .

Fenomena penetrasi Islam ke Jawa pedalaman pada abad ke-16 dan 17 $\mathrm{M}$, menghasilkan dikotomi dalam pemahaman maupun penerapan Islam di kalangan umat Islam Jawa, antara: Islam model abangan di daerah agraris 
Jawa pedalaman dan Islam putihan gaya pesisiran. Keduanya bersinggungan dalam satu wadah budaya (melting pot) budaya Mataram, wilayah Kraton Mataram Islam.

Mataram pada masa awal pemerintahannya, era Senopati dan Panembahan Krapyak, mengalami banyak masalah dan perbenturan sosial politik dan budaya, itu wajar mengingat era ini merupakan era konsolidasi kekuasaan, bagi sebuah kekuasaan model heredity. Dinasti Mataram pada awal berdirinya dianggap tidak legitimate oleh penduduk muslim pesisiran, karena panembahan Senopati dianggap memotong dan merebut jalur keturunan Demak dan Pajang, kondisi itu melahirkan perlawanan dari berbagai wilayah kekuasaan Islam di seluruh Jawa eks Demak (Lombard, 2000). Perlawanan dan pertentangan politik banyak menguras tenaga Mataram, meskipun Senopati raja pertama dan Krapyak raja kedua dapat memenangkan pertandingan dengan gemilang, namun cost politiknya cukup mahal, sebab pertentangan dengan kelompok Islam terus menerus berlanjut pada era setelahnya. Diantaranya yang dirasakan Sultan Agung raja ketiga, perlawanan keturunan Sunan Giri di Gresik, pertentangan dengan pusat-pusat pesantren seperti Tembayat dan Kajoran, pertentangan dengan para pengikut Sunan Ampel di Madura. Bahkan nantinya timbul berbagai persoalan di era setelahnya yaitu perlawanan Sunan Alit pada zaman Amangkurat I yang berakhir pembantaian 6.000 kaum muslim di depan istana Plered (Graaf, 1986). Selain itu, terjadi pemberontakan Trunajaya dari Madura yang dibantu oleh Pesantren Kajoran pada zaman Amangkurat II yang sempat berhasil menduduki Kraton dan memaksa Kraton Mataram pindah dari Karta (di Yogjakarta) ke Kartasura (Lombard, 2000). Namun perlu digaris bawahi bahwa meskipun skala pertentangan itu demikian kuat, sesungguhnya tidaklah terjadi pertentangan agama, sebab Sultan Agung telah memberi dasar budaya yang kuat bagi Mataram. Untuk tujuan itu diperlukan interrelasi pemikiran atau unite concept antara kedua budaya itu agar dijadikan sumbu pemersatu, dalam bentuk akulturasi dan simbiosis yang harmonis, unite concept inilah dalam akajian ini disebut integrasi (Maurice, 1985; Poerwanto, 1999).

Problem sosial agama itu pada akhirnya diolah oleh Sultan Agung sehingga melahirkan konsep pemersatu (unite concept) dalam bentuk karya sastra kepujanggan yaitu risalah Serat Sastra Gending. Penelitian ini ingin mengkaji "Serat Sastra Gending" dari sisi content isinya, tafsiran 
pemahamannya, dan peranannya dalam membangun dinamika sosial dan budaya, khususnya akulturasi paham agama bagi Mataram.

Kajian ini dimaksudkan untuk menemukan pola integrasi pemahaman agama yang akulturatif dalam sebuah teks sastra sebagai pusat analisisnya, dengan mengambil batasan zaman kekuasaan Sultan Agung yaitu pada awal Abad ke-17, karena pada era itu dinamika kekuasaan Mataram mencapai tahap kejayaan dan kesejahteraan sehingga bangunan pemikiran berkembang dengan baik, di samping itu situasi pemikiran agama yang bertentangan antara putihan dan abangan mencapai puncaknya akibat dari penetrasi Islam Pesisir ke pedalaman Jawa, pasca runtuhnya kekuasaan politik Demak-Pajang dan usainya dakwah era wali Sanga, sedangkan secara spasial dibatasi pada wilayah teritorial Mataram.

\section{Kajian naskah dan sejarah Serat Sastra Gending}

Kajian naskah dan sejarah, khususnya Jawa Islam, hingga saat ini masih jarang diminati oleh para Sarjana keislaman. Maka sangat jarang atau boleh dikata sangat minim karya tulis yang dihasilkan atas sebuah kajian terhadap naskah Jawa khususnya era Demak, Pajang dan Mataram. Naskah Sastra Gending sendiri masih sedikit yang mengkaji, meskipun naskah ini nyata karya sastra sebuah imperium kasultanan yang menjadi sumber ide kebijakan Negara. Namun mengingat keterbatasan bahasa Jawa maupun aksara Caraka dari para peneliti, maka Sastra Gending sejauh ini belum benarbenar dikaji secara lebih luas ataupun mendalam.

Berbagai penelitian pun telah dilakukan berkaitan Serat Sastra Gending ini pada beberapa tahun belakangan. Penelitian tersebut antara lain oleh Zaenudin, (2014) yang mengkaji mengenai isi dari Serat Sastra Gending ini. Lalu Kurnialoh, (2015) peneliti bagaimana kajian Serat Sastra Geding ini diimplementasikan dalam Pendidikan agama Islam. Ada pula Asmara, (2017) yang mengkaji bagaimana peran pada raja-raja berkaitan dengan berbagai karya sastranya, dan beberapa diantaranya adalah Serat Sastra Gending yang dikembangkan oleh Sultan Agung sebagai raja. Sedangkan Purwanto, dkk ,(2018) yang mengkaji bagaimana Serat Sastra Gending di implementasikan dalam praktik pemaknaan.

Penelitian tentang Serat Sastra Gending, sejauh ini telah dilakukan dari sisi philology. Sehingga kajian ini berpijak pada hasil kajian philology yang telah dilakukan oleh Lembaga Javanologi yang diadakan atas kerjasama 
Universitas Gajah Mada Yogyakarta dengan KITLV kedutaan Belanda di Jakarta (Supajar, 1988; Supajar \& Prihantoro, 2001).

Hasil penelitian itu hingga saat ini menghasilkan sastra terjemahan atas serat yang sebelumnya disimpan oleh K.P.H. Suryaningrat dan K.P.H. Sasraningrat berbentuk tulisan tangan dalam simpanan naskah Pura Pakualaman Yogyakarta. Naskah ini mengandung ajaran mistik teosofi akulturatif yang diakukan sebagai ajaran Sultan Agung. Isinya merupakan perbandingan antara sastra dengan gending, syari'at dan hakekat, Tuhan danciptaan dalam manunggaling kawula Gusti, Sri Kresna dan Dewa Wisnu dalam ajaran pedalangan Jawa (Supajar, 1988).

Penelaahan yang dilakukan terhadap beberapa penelitian sebelumnya memberikan gambaran masih lemah kedalaman kajiannya terhadap naskah Jawa khususnya yang berbasis Caraka (aksara Jawa); selain itu, siapa Penulis naskah ini masih kabur, hanya disandarkan kepada Sultan Agung, namun melihat struktur bahasa pada naskah maka wajar bila tulisan ini ditulis oleh Sultan Agung atau Pujangga terdekatnya yang diilhami dari pola piker sang Raja, sebagaimana disampaikan sendiri dalam naskah.

Yang menarik dari kajian sastra dalam naskah Sastra Gending adalah bagaimana seorang Sultan pada era yang masih sangat terbatas jaringan lalu lalang pengetahuan telah berpikir cerdas membuat sebuah tali pengikat (intgegrasi ajaran agama) antar warga penduduk Mataram sehingga tidak terjebak pada konflik yang berkepanjangan akibat beda agama dan beda paham. Dan ternyata pemikirannya itu setara dengan pemikiran yang berkembang di belahan dunia lain abad itu (17 M) sebagaimana yang terjadi di Turki, India maupun Aceh. Integrasi terbukti telah dapat menjadi solusi menuju keutuhan, keharmonisan hidup sebuah bangsa, dalam hal ini dapat dikaji antara lain memalui budaya (Mawardi, 2011; Umikalsum \& Fauzan, 2019).

Kebudayaan adalah dinamika keseluruhan hidup manusia dalam ide maupun karya (Kroeber, 1948). Kebudayaan dari setiap bangsa atau masyarakat terdiri dari unsur-unsur besar yang bersifat universal (universals culture) dan dapat dibagi menjadi kebudayaan yang lebih kecil berupa bagianbagian kebudayaan dalam bentuk aktifitas budaya (cultural activity), selanjutnya dibagi lagi ke dalam unsur yang lebih kecil yang disebut trail complex (Taylor, 1958). 
Perkembangan merupakan watak budaya, seiring perkembangan nalar dan kreativitas manusia. Dalam perkembangannya, budaya acapkali bertemu dan berhadapan dengan budaya lain sehingga terjadilah dialektika antar budaya. Dialektika itu, menurut Hegel, membentuk pola segitiga yaitu tesis, antithesis dan sintesis. Dialektika itu merupakan dampak dari komunikasi dan relasi budaya.

Bentuk relasi antara dua kebudayaan yang berbeda bisa beragam, bisa berbentuk konflik ataupun simbiosis (symbiotic culture). Bentuk symbiotic adalah pertemuan antar budaya yang saling menerima yaitu akulturasi dan integrasi, dimana kebudayaan lokal dapat menerima nilai dari kebudayaan luar tanpa kehilangan jati dirinya. Proses akulturasi itu berlangsung secara bertahap, mulai transmisi ide-ide, evaluasi oleh pihak yang terlibat, dan pada akhirnya terjadi integrasi (Ismail, 2012; Soekanto, 2011).

\section{Metode}

Penelitian ini selain mengkaji content analysis berupa ajaran akulturasi dalam naskah Serat Sastra Gending ajaran Sultan Agung, berupa ide-ide integrasi yang brillian dalam Serat Sastra Gending yang berhasil mewujudkan hidup harmonis ditengah masyarakat Mataram. Dari semangat inilah, maka timbullah nilai-nilai persatuann yang mampu menegasikan setiap perpecahan. Meskipun masyarakat sadar bahwa kedatangan agama Islam telah menganulir kepercayaan mereka yang telah terinternalisasi lama dalam benak masyarakat Mataram, pewaris Hindu Majapahit di pedalaman Jawa.

Untuk menemukan ide-ide yang dapat dipetik dari naskah itu, dilakukan analisis dengan hermeneutika sosial (social hermeneutics), yang diartikan sebagai:interpretation of human personal and social action" (Runes, 1976) yang hendak dijelaskan melalui hermeneutika adalah bagaimana menjelaskan isi sebuah teks agama kepada masyarakat yang hidup dalam tempat dan kurun waktu yang berubah (berbeda) dari pihak autor. Dengan demikian problema hermeneutika selalu berhubungan dengan proses pemahaman (understanding), penafsiran (interpretation) dan penerjemahan (translating) atas sebuah pesan (lisan atau tulisan) untuk selanjutnya disampaikan kepada masyarakat yang hidup dalam dunia yang berbeda (Bizawie, 2002).

Menurut Palmer terdapat cabang-cabang hermneutika (Palmer, 1969), salah satu cabang yang berbicara tentang sosial adalah social hermeneutics, 
berisi interpretasi terhadap pribadi manusia beserta tindakan-tindakan sosialnya. Pada model keenam inilah kajian terhadap Serat Sastra Gending akan dianalisis.

\section{Identifikasi Naskah Serat Sastra Gending}

Naskah Serat Sastra Gending dapat ditemukan dalam bentuk bundel tulisan Jawa yang ditulis ulang oleh K.P.H. Suryaningrat dan K.P.H. Sasraningrat dalam simpanan naskah Pura Pakualaman Yogyakarta. Secara resmi, Departemen Pendidikan dan Kebudayaan, Direktorat Jendral Kebudayaan, Proyek Penelitian dan Pengkajian Kebudayaan Nusantara (Javanologi) telah melakukan proyek penelitian terhadap naskah ini, dan dibukukan dalam bentuk transliterasi huruf latin dan telah diterjemahkan ke dalam bahasa Indonesia. Ketikan naskah ini dapat ditemukan dalam katalog naskah kode 78 M 376 underscore 105.248 di perpustakaan Ignasius Yogyakarta.

Naskah Sastra Gending terbitan Javanologi, terdiri dari dua bagian. Bagian awal adalah transliterasi huruf latin dengan tetap menggunakan bahasa Jawa, berbentuk ketikan manual sebanyak 24 halaman kertas HVS folio. Sedangkan bagian kedua merupakan terjemahannya, juga diketik manual sebanyak 29 halaman. Terjemahan ini dilakukan oleh Ki Y. Padmapuspita.

\section{Penulis Naskah Sastra Gending}

Pengarang serat ini tidak disebutkan, namun secara umum dipahami sebagai ajaran Sultan Agung. Menurut penilaian penulis, secara eksplisit dalam tulisan ini menyebut Sultan Agung dengan kata-kata "jeng" atau "kanjeng" sebuah kata penghormatan terhadap raja yang berarti "Yang Mulia", sebutan itu menunjukkan bahwa penulisnya bukanlah Sultan Agung sebagaimana disangkakan di depan, melainkan orang lain.

Meskipun kita menemukan kenyataan bahwa penulis naskah ini bukan Sultan Agung pribadi, namun bisa dipastikan dia adalah orang dari lingkungan dekatnya apakah juru tulisnya, pengikutnya atau paling tidak orang yang telah mengenal dengan baik sikap dan cara berfikir Sultan Agung, sebagimana ditulis dalam Mukaddimah, Pupuh Sinom, bait 2:

\section{Lir mangimur manuhara}


Mamasuh malaning budi, Kang mupakat sinaksenan, Dening para sarjana-di, Kang tuhu anetepi, Ing reh pralambang ing ayun, Yeku riwayat-ira, Jeng sultan Agung Matawis, Kang minangka paugeraning muktakat.

(Seperti bunyi pelipur lara, menarik bahasanya, Mencuci cacat dan noda di dalam budi manusia, Demikianlah dengan sepakat diakui, Oleh para sarjana dan para ahli, Yang telah dengan sungguh-sungguh menaati, Segala sesuatu yang tersirat di dalam syair di muka, Syair yang memuat petuah wasiat utama, Warisan yang mulia Sultan Agung Mataram, Dijadikan pedoman yang benar menurut kesepakatan)

Melalui pendahuluan naskah itu, dapat dipahami bahwa penulis dengan sengaja menyampaikan tulisan ini dalam rangka memperingati Sultan Agung dengan cara menulis ulang petuah-petuah dan ajarannya. Agar warisan ajaran sastra Sultan Agung itu itu dapat diikuti oleh para turunnya dan bermanfaat bagi sekalian orang banyak, melihat pengakuan penulis bahwa dia merujuk pada ajaran Sultan Agung, maka naskah ini dapat dikategorikan sebagai naskah yang berisi pemikiran zaman Mataram, Sultan Agung.

\section{Ringkasan Naskah Serat Sastra Gending}

Naskah ini terdiri dari 5 (lima) bab yang dijabarkan dalam 72 bait. Bab pertama terdiri 13 bait, tembang Sinom, dimulai dengan Mukadimah (pendahuluan) 3 bait, berisi puji-pujian kemasyhuran Sultan Agung yang telah meninggalkan warisan ajaran sastra dan pedoman hidup, dan perhatian Sultan terhadap keserasian Sastra Gending yang harus dipelajari oleh anak cucunya, baik yang berasal dari bahasa kawi, caraka basa (peribahasa), maupun bahasa Arab. Sekalian bahasa itu harus dapahami sastranya, makna bahasanya, bahkan kedalaman filosofinya. Beliau bersabda bahwasanya tidak akan diakui sebagai keturunannya yang tidak tahu tentang tembang kawi dan sekalian sastra itu (bait 6). Memahami Sastra Gending tidak hanya paham sastra dan irama saja, melainkan di dalamnya terkandung ajaran hakekat dan syariat secara seimbang, apabila seseorang rusak gendingnya maka rusak pula solatnya. 
Bab kedua, terdiri 12 bait, nama tembang Asmarandana, isi dari bait 1 dan 2, mengenai perdebatan ahli gending dan ahli sastra bahwa dalam berolah sastra dan gending seseorang tidak perlu berbantahan tentang mana yang lebih utama sastra atau gending, keduanya menduduki peran yang sama penting. Bait 3-6 sendiri membahas soal gending, gending menempati kedudukan hakekat yang membahas tentang Tuhan, sumbernya dari pikiran manusia, menyatunya Tuhan dengan manusia menjadi tema pikiran yang tinggi sehingga gending dianggap lebih tinggi dari sastra. Bait ke-7, membahas tentang sastra, lahirnya belakangan dan berlaku sebagai alat kenegaraan, pedoman keseharian, pemutus hukum keperdataan (sastra ibarat hukum syariat). Bait ke 8-12, membahas tentang Dat Mutlak, tetapi hakekatnya sastra mengandung huruf alif sebuah lambang kegaiban Tuhan yang tidak dapat dicapai oleh pikiran, yakni ghaibul-luwiyah (al-ghâib alUlûhiyah, pen). Sastra hakekatnya adalah Dat Mutlak yang disebut sebagai la ta'ayun adapun wujudnya adalah gending setelah alif menjadi kenyataan, sastra adalah roh ilapi (ruh idhofi) dalam konsep rahasia Tuhan sedangkan gending adalah alam khorijiah (alam luar) atau kenyataan makhluk, sastra adalah cipta dan gending adalah karsa.

Bab ketiga, terdiri dari 11 bait, nama tembang Dandang-Gula (hartati), isinya tentang kegaiban Tuhan (ajaran martabat tujuh dalam wahdat alwujûd). sastra ibarat kegaiban seperti anak dalam kandungan ibunya, setelah segala sesuatunya lengkap disebut dalam ilmu Tuhan a'yan tsabitah, setelah keluar (a'yan kharijah, pen) baru diketahui bayi itu jenis kelaminnya, itulah gending yang mengiringinya. Dalam bercermin sastra adalah yang bercermin, bayang-bayangnya adalah gending yang setelah lenyap pada cerminnya akan kembali ke hakekat sastranya. Sebagaimana gema dan suara, ikan dan samudera, gending dan juru gamelan, yang pertama adalah gending dan kedua adalah sastranya.

Bab keempat, terdiri 17 bait, nama tembang Pangkur, isinya ajaran bahwa dalam huruf jawa yang dua puluh ( $h a-n a-c a-r a-k a)$ juga mengandung ajaran akadiyat, wahdat jati dan wakidiyat seperti konsep martabat dalam Islam. dalam silsilah Dewa, Sang Hyang Manikmaya ibarat papan tulis yang bersih sedang Hyang guru adalah tintanya, sastra ibarat papan tulis dan gending ibarat tinta, seperti dalang dengan wayang. Kresna dan Wisnu adalah Dwi Tunggal, Hyang Wisnu ibarat sastra dan Kresna adalah gendingnya. Hyang Wisnu menjelma menjadi Kresna dalam rangka menyelamatkan dunia dan menjaga keadilan diatas bumi. Tokoh-tokoh yang disebutkan dalam 
naskah itu adalah sebuah perwujudan dari konsep emanasi Tuhan terhadap mahluk.

Bab kelima, terdiri 19 bait, nama tembang Durma, isinya kritik terhadap orang yang mengagungkan salah satu dari sastra-gending dengan berpihak pada akal pikiran saja. Orang yang demikian akan kehilangan arah yang dituju dan terjadi salah paham dalam hidup. Karena hakekat ' $a d a$ ' itu timbul dari 'yang tak ada', sebaliknya persoalan 'yang tidak ada' timbul karena sesuatu 'yang ada'. Maka hendaknya seseorang berpegang pada syari' at agar selamat dalam 'kayun fidari' maksudnya 'hayyun fiddaraini" selamat dalam hidup di dua rumah yaitu dunia dan akherat. Karena pada hakekatnya Kresna itu menjadi mulia oleh wujud penjelmaan Dewa Hari.

\section{Sultan Agung dan Problem Budaya Mataram}

Nama kecilnya adalah Raden Mas Rangsang, menurut ensiklopedi Nasional Indonesia, dia lahir pada tahun 1591 M (Tim Penyusun, 1988), dari seorang ayah yang merupakan raja Mataram ke-II (kedua) bergelar Panembahan Seda Ing Krapyak, dia cucu dari pendiri dinasti Mataram yang bergelar Panembahan Senapati Ing Alaga. Sedangkan Ibunya bernama Dyah Banowati seorang puteri dari Pangeran Benawa, cucu Sultan Pajang Hadiwijaya keturunan dinasti Pengging, dimana masa bujangnya terkenal dengan sebutan Jaka Tingkir. Apabila silsilah ibunya dirunut maka bisa disebut bahwa ibunya berasal dari keturunan asli (cucu Buyut) dari Sultan Demak terakhir Sultan Trenggana, melalui Sultan Pajang.

Panembahan Seda Krapyak raja kedua Mataram, ayah Sultan Agung, nama kecilnya adalah Mas Jolang, setelah meninggal pada tahun 1613 di tempat perburuan yang disebut Krapyak, maka diberi gelar Pangeran sebutan Panembahan Sedo Ing Krapyak (Tim Penyusun, 1988). Sebagai penggantinya dinobatkan Raden Mas Rangsang pada tahun 1613 (Aji \& Ahmad, 2014), bergelar Panembahan Hanyakrakusuma, Prabu Pandita Hanyakrakusuma, atau Susuhunan Agung Hanyakrakusuma, pada tahun 1640 menggunakan gelar Sultan Agung Senapati ing Alaga Abdurahman, kemudian pada tahun 1641 ditambah gelar dari syarif Makkah yakni Sultan Abdullah Muhammad Maulana Matarami (Aji \& Ahmad, 2014).

Keutamaan Sultan Agung banyak dipuji dalam naskah-naskah Jawa, diantaranya Babad Sultan Agung. Bentuk fisiknya digambarkan dadanya bidang, badan kekar dengan otot-otot kuat akibat latihan "keprajuritan" yang 
teratur dan keras. Sikapnya tenang dan berwibawa tinggi karena kebijaksanaan yang sangat agung. Hatinya lembut kepada rakyat, namun sangat kuat pendiriannya. Dia raja yang berwibawa, cerdas, sekaligus memiliki wawasan yang jauh ke depan (Zakaria, 2011). Dalam Babad Imogiri, dijelaskan bahwa dia di satu sisi di emban (asuh) Sunan kalijaga, di sisi lain di emban Ratu Laut Selatan, bahkan pernah bertemu Syarif Makkah dan mendapat hadiah Surban Hitam peninggalan Nabi Muhammad saw.

Pada zaman pemerintahannya Islam berkembang dengan pesat, sementara kaum muslim Mataram terdikotomi dalam ajaran tasawuf ortodoks peninggalan para Wali, dan mistik heterodoks yang sangat ketat melakukan tradisi dan upacara budaya yang berasal dari warisan budaya agama Hindu-Budha era agama Majapahit. Pertentangan itu menimbulkan problematikan sosial budaya, sebab para pengamal Islam pesantren yang ortodoks meganggap kaum abangan masih dipenuhi dengan budaya kekafiran, kemusyrikan, khurofat dan upacara-upacara kebid'ahan.

Menyikapi problem itu, maka Sultan Agung segera menangkap kemungkinan terjadinya pertentangan antar masyarakat Islam dan Hindu pedalaman. Maka untuk mempertemukan dua ajaran itu dirancanglah integrasi antar ajaran agama melalui sistem budaya sehingga perlu dirancang United Concept. Maka dilakukanlah model dakwah dengan cara membuat formulasi tengah antara dua kutub pertentangan itu, yaitu naskah Serat Sastra Gending.

\section{Konsep integrasi dalam Sastra Gending: Integrasi Konsep Agama dalamTeosofi Islam-Jawa}

Emanasi Islam dalam Sastra Gending dijelaskan dalam naskah, bahwa hakekatnya sastra itu ruhnya dan gending itu fisiknya. Proses dari ruh yang gaib menuju fisik yang lahir melalui sebuah tahapan yang dalam istilah teosofi disebut proses emanasi, yaitu sebuah proses dimana Tuhan dalam menciptakan manusia melalui pancaran ruh dzat-Nya, pancaran itu melalui martabat-martabat penciptaan, konsep itu terdapat dalam ajaran paham waḥdat al-wujûd atau manunggaling kawula Gusti.

Tuhan adalah Dzat yang Mutlak azali abadi, berada dengan dirinya sendiri secara transenden. Dia akan mewujud apabila dirinya telah menjadi sebuah sebutan "Alif". Bab II bait 8: 
Dat Mutlak dipun wastani

Myang la-takyun ingaranan,

Durung kahana salire,

Maksih wang uwung kewala

Iku jatining sastra,

Anane gendhing satuhu

Dupi alip wus kanyatan

(perihal mengenai dzat mutlak, disebut la ta'ayyun, belum ada segala-

galanya, masih berupa angkasa kosong (awang-uwung), itulah hakekat sastra, wujudnya hanya gending gamelan semata, setelah Alif menjadi kenyataan).

Kemudian ketika berkehendak menciptakan semesta dan manusia, Tuhan beremanasi dari a'yan tsabitah (entitas yang gaib) menuju a'yan kharijah (entitas yang lahir) melalui martabat-martabat, tiga martabat ghaib (ahadiyat, waḥdat dan wahidiyat) dan empat martabat dzahir (alam arwah, alam mitsal, alam ajsam dan insan kamil) (Afifi, 1989; Noer \& Azhari, 1995). Manusia sebagai entitas ciptaan Tuhan yang sempurna adalah insan kamil sebagai wujud emanasi Tuhan secara paripurna. Sehingga karenanya, manusia ibarat bayang-bayang Tuhan diatas bumi, sebagaimana cermin maka hakekat yang bercermin adalah Tuhan dan manusia adalah bayangbayangnya saja. Disebutkan bab II bait 9:
Katandhan ing roh-ilapi
Goning alam korijiyah
Iku wit ngakal anane
Dennya wit wruh ing dat mutlak
Saking kono kang marna,
Iku kawruhana sagung,
Endi ingkang luhur andhap.
(itulah petanda dari roh ilapi (ruh idlofi), termasuk soal alam khorijah, itulah permulaan adanya akal pikiran, permulaan tahu tentang dat mutlak, dari situlah timbul gambaran, hendaknya menjadi pengetahuan kalian, mana yang tinggi mana yang rendah).

Manusia sebagai bayang-bayang Tuhan dalam cermin. Disebutkan dalam bab III bait ke 9, tiga baris akhir: "...iku upaminipun, kang ngilo jatining sastra, kang wayangan gending, sirnaning cermin, manjing jatining sastra" artinya (...itu bagai perumpamaan, yang mengaca (Tuhan) sejatinya sastra, bayangannya (manusia) adalah gending, apabila hilang cerminnya, maka muncullah sejatinya sastra/Tuhan semata). Ungkapan ini juga dapat dipahami bahwa dalam jalan mistik (sufi), hakekat manusia adalah bayang-bayang Tuhan (emanasi Tuhan), bagaikan Tuhan yang berkaca di depan cermin. 
Apabila cerminnya dihilangkan maka pada hakekatnya yang ada dalam kehidupan dunia adalah Tuhan semata.

Perbandingan antara a'yan tsabitah dan a'yan kharijahdalam naskah itu ibarat kegaiban bayi yang masih ada dalam kandungan sang ibu, yang tahu hanya Tuhan. Sesudah bayi lahir dari kegaiban barulah keadaan itu menjadi kenyataan, sastra sudah mewujud dalam bentuk gending. Perwujudan itu diiringi dengan keimanan, yaitu ucapan: "la ilaha illallah" (naskah Bab III, bait 1).

\section{Emanasi dalam Konsep Teosofi Jawa}

Sultan Agung mengawali penjelasan pada bagian ini dengan menyatakan bahwa, Konsep teosofi yang disampaikan dalam sastra Islam (Arab) pada dasarnya dapat dijumpai pula dalam paham teosofi dalam sastra Jawa, keduanya berirama dengan gending, karena gending itu pada hakekatnya berasal dari kreatifitas akal manusia. Disampaikan pada bab IV pupuh pangkur bait 1:

Kawuri pangestining byat,

Tuduhireng sastra Arab lan gendhing

Sokur yen wis pada rujuk

Nadyan aksara Jawa

Nora keri lawan gendhing asalipun

Gendhing wit purbaning akal

Kadya kang wus kocap ngarsi

(Kita tinggalkan tentang tujuan niah, yang petunjuknya kita dapatkan dalam sastra Arab dan gending, syukurlah, jikalau kita semua telah setuju, demikianlah sesungguhnya mengenai sastra Jawa, pun juga asalnya tak kalah dari gending, gending yang berasal dari akal manusia, seperti telah kita bicarakan di muka)

Dijelaskan bahwa paham manunggaling kawula Gusti dapat ditemukan dalam konsep huruf Jawa yang dua puluh. Yaitu Ha-na-ca-ra-ka merupakan wujud dari martabat akadiyat, sedangkan kelompok huruf da-ta-sa-wa-la merupakan wujud martabat wahdat-jati. Dalam pupuh IV (pangkur) bait 2 disebutkan:

Kanang sastra kalih dasa

Wit pangestu tuduh kareping puji,

Puji asaling tumuwuh,

Mirit sing akadiyat, 
Sastra Ha Na Ca Ra Ka pituduhipun, Dene kang Da Ta Sa Wa La, Kagentyaning Kang amuji

(Huruf Jawa yang duapuluh banyaknya, itu membawa petunjuk tentang puja-puji, puji terhadap yang menjadi asal mula hidup umat, menurut Akadiyat, pada huruf $\mathrm{Ha} \mathrm{Na} \mathrm{Ca}$ Ra Ka mendapat petunjuknya, adapun Da Ta Sa Wa La berganti soal mengenai si Pemuji, itu menurut wahdat Jati/bait berikutnya)

Adapuan huruf pa-da-ja-ya-nya merupakan martabat wahidiyat, ketiganya berada pada martabat batin yang dalam konsep ini berada pada kedudukan sastra, kemudian dari ketiganya terwujud ma-ga-ba-tha-nga martabat lahir (khariji) berupa ciptaan Tuhan di muka bumi, yang utama adalah manusia yang berkedudukan sebagai gending-nya. Disebutkan dalam pupuh IV (pangkur) bait 3:

Wahdat Jati kang rinaras,

Ponang Pa Dha Ja Ya Nya, angyakteni,

Kang nuduh lan kang tinuduh,

Sami santosanira,

Kahananya Wakidiyat Pambilipun

Dene kang Ma Ga Ba Tha Nga,

Wus Kanyatan jatining Sir

(menurut Wahdat Jati yang dibahas, huruf pa dha ja ya nya, mengikrari. Yang memberi petunjuk dan yang menerima petunjuk, ke dua-duanya sama-sama kuatnya, itu menurut ilmu: Wakidiyat, seangkan huruf ma ga ba tha nga memberi isyarat, menegaskan hakekat rahasia).

\section{Emanasi dalam Konsep NitisTeosofi Hindu}

Dalam paham agama Hindu (sering disampaikan dalam lakon pewayangan), bahwa proses ciptaan dalam martabat gaib masih dalam wujud Sang Hyang Nur-Cahya dan Nur-Rasa, kemudian mewujud dalam alam lahir menjadi Sang Hyang Guru atau Hyang Manik Maya. Awalnya adalah Hyang Resi Kaneka yang lebih tua dimudakan dan lebih muda dituakan, keadaan ini menurut Sultan Agung mengandung maksud yang masih dirahasiakan.

Pupuh IV Bait 7, disebutkan:

Kawedar Cipta Pangrasa

Hyang Nur-Cahya Nur-Rasa wus kawuri,

Kagentyaning Sang Hyang Guru 


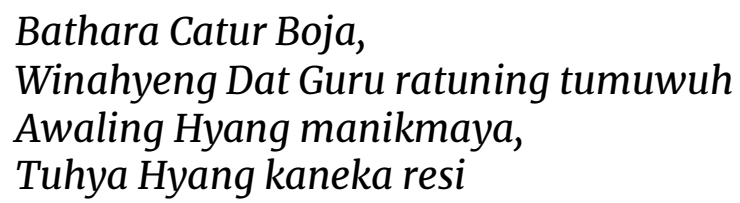

(ajaran cipta pangrasa, Hyang Nur-Cahya Nur-Rasa telah kita lalui, berganti soal sekarang mengenai: Sang Hyang Guru, yang juga disebut Bathara Catur Boja, Ia diwujdukan menjadi dat Guru yang merajai hidup semua, awal Hyang Manikmaya adalah Hyang Rsi Kaneka).

Maksudnya adalah bahwa Sang Hyang Guru, dalam ajaran pewayangan sebagai rajanya para Dewa yang bersemayam di Kahyangan Indraprastha, merupakan perwujudan emanasi (nitis) dari Hyang Manikmaya. Dia inilah Mahadewa atau Bathara Shiwa yang Agung, salah satu dari Trimurti (Dewa Hindu).

Bagaimana emanasi itu terjadi, ibarat tinta dengan papan tulisnya. Pupuh IV Bait 10, Manikmaya ibarat tulisan yang bersih, sedangakan Hyang Guru adalah tintanya, sastra ibarat papan tulis sedangkan gending ibarat tinta yang telah jatuh di atas papan tulis itu, kalau tintanya lebih dulu, akan timbul pertanyaan dimana jatuhnya tinta.

\section{Papan moting kawisesan \\ Manik-maya purbaning papan wening \\ Tulise mangsi Hyang Guru \\ Sastra upama papan \\ Gending akal upama mangsi wus dawuh \\ Yen dihina mangsinira \\ Ngendi gone tibeng tulis}

Mengenai makna sastro dalam konsep Wisnu yang menitis pada Sri Kresna, disebutkan dalam naskah bahwa Kresna adalah perwujudan (titisan) Dewa Wisnu di dunia, konsep ini perlu dipahami sebagai wujud tauhid (kesatuan), jangan mementingkan gendingnya saja. Jadi gendingnya adalah konsep nitis-nya Wisnu dalam diri Kresna, namun dalam tataran sastranya, sesungguhnya konsep itu adalah konsep tauhid dalam ajaran Islam. Dalam pupuh Durma V bait 1:

Durmaning kang ngluhuraken gending (akal)

Pangestinireng tokit, Hyang Wisnu lan Kresna, Nuhung Wisnu Kewala, Hyang Kresna datan ngesti 
Nadyan lebura

Kang jagad tan praduli

(kelemahan orang yang mengagungkan gending (akal), pandangan di dalam tauhidnya, mengenai satuan Wisnu-Kresna, hanya Wisnulah yang dipandangnya, Seri Kresna tidaklah diingatnya, meskipun dunia akan hancur karenanya, hal itu tidaklah dipedulikannya).

Konsep intergrasi dalam 3 (tiga) ranah pemikiran Serat Sastra Gending di atas, dapat disederhanakan dalam akulturasi budaya dalam bentuk bagan berikut ini:

\begin{tabular}{|c|c|c|c|}
\hline \multirow[b]{2}{*}{ No } & \multicolumn{2}{|c|}{ Akulturasi } & \multirow[b]{2}{*}{ Paham/ajaran } \\
\hline & Martabat Sastra/gaib & $\begin{array}{c}\text { Martabat } \\
\text { Gending/lahir }\end{array}$ & \\
\hline 1 & $\begin{array}{l}\text { Rahasia yang } \\
\text { mengandung makna- } \\
\text { makna kebatinan, } \\
\text { nilai-nilai hakekat. }\end{array}$ & $\begin{array}{l}\text { Syari'at, pelaksanaan } \\
\text { dalam kehidupan, } \\
\text { jelmaan dari cipta dan } \\
\text { rasa }\end{array}$ & $\begin{array}{lr}\text { Umast } & \text { islam } \\
\text { harus seimbang } \\
\text { dalam memahami } \\
\text { hakekat dengan } \\
\text { syari'at }\end{array}$ \\
\hline 2 & $\begin{array}{l}\text { Martabat batin pada } \\
\text { alam gaib ketuhanan: } \\
\text { Ahadiyah, Wahdah, } \\
\text { wahidiyah }\end{array}$ & $\begin{array}{l}\text { Martabat lahir } \\
\text { (syuhudi) pada alam } \\
\text { nyata ciptaan: alam } \\
\text { arwah, alam mitsal, } \\
\text { alam ajsam dan insan } \\
\text { kamil. }\end{array}$ & $\begin{array}{l}\text { PahamWahdat al- } \\
\text { Wujûdmemiliki } \\
\text { wujud batin dan } \\
\text { lahirsecara } \\
\text { seimbang }\end{array}$ \\
\hline 3 & $\begin{array}{l}\text { Tiga kelompok huruf } \\
\text { jawa duapuluh } \\
\text { (martabat batin): ha- } \\
\text { na-ca-ra-ka } \\
\text { (ahadiyah), da-ta-sa- } \\
\text { wa-la (wahdah), pa- } \\
\text { da-ja-ya-nya } \\
\text { (wahidiyatjati) }\end{array}$ & $\begin{array}{l}\text { Satu kelompok huruf } \\
\text { Jawa terakhir } \\
\text { (martabat lahir): } M a- \\
\text { ga-ba-tha-nga } \\
\text { terwujud dalam } \\
\text { ciptaan yang nyata } \\
\text { (sosok manusia } \\
\text { sebagai cerminan } \\
\text { Tuhan) }\end{array}$ & $\begin{array}{lr}\text { Pola lahir } & \text { batin } \\
\text { dalam } & \text { paham } \\
\text { Jawa } & \text { Caraka } \\
\text { serupa } & \text { dengan } \\
\text { emanasi } & \text { dalam } \\
\text { Islam } & \end{array}$ \\
\hline \multirow[t]{2}{*}{4} & $\begin{array}{l}\text { Hyang Manikmaya, } \\
\text { entitas batin (a'yan } \\
\text { tsabitah) }\end{array}$ & $\begin{array}{l}\text { Menjelma dalam diri } \\
\text { Bathara Guru, entitas } \\
\text { lahir (a'yan kharijah) }\end{array}$ & \multirow{2}{*}{ 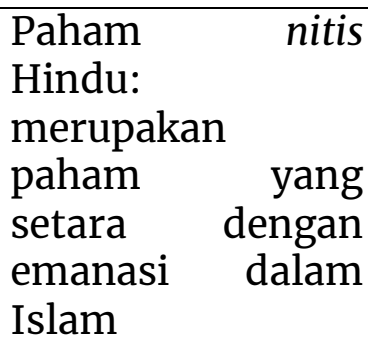 } \\
\hline & $\begin{array}{l}\text { Hyang Wisnu, entitas } \\
\text { batin (a'yan tsabitah) }\end{array}$ & $\begin{array}{l}\text { Menjelma dalam diri } \\
\text { Sri Kresna, entitas } \\
\text { lahir (a'yan kharijah) }\end{array}$ & \\
\hline
\end{tabular}


Peneliti berkesimpulan bahwa penulis "Serat Sastra Gending" ini secara cerdas ingin mengajarkan paham teosofi melalui simbol-simbol sastra dan gending, yang menurutnya telah membentuk komposisi harmonis dan indah dalam lagu-lagu aransemen musik Jawa yang indah dan sangat merakyat. Hal itu merupakan simbol ajaran yang akulturatif. Akulturasi dalam Sastra Gending itu mampu mewadahi tiga ranah teosofi yang berkembang dalam diskursus pemikiran mistik di Mataram yaitu: teosofi Islam, teosofi Jawa dan teosofi Hindu secara bersamaan. Pertemuan itu pada hakekatnya merupakan integrasi dan harmonisasi hubungan agama Islam, Hindu dan Jawa. Pemahaman yang setara dan senyawa dasar dari sebuah pola hubungan hidup beragama antara warga masyarakat.

\section{Kesimpulan}

Penyebaran Islam dari pesisir ke pedalaman pada zaman Mataram, membawa orientasi baru dari pola Islam ortodoks menuju heterodoks, atau Abangan dan Putihan. Perubahan paradigma itu terjadi akibat dari jauhdekatnya pola ajaran itu dengan sisa-sisa peninggalan budaya agama HinduBuddha yang telah membentuk agama Jawa pra Islam. Sultan Agung, mengetahui benar pertentangan dalam budaya agama dalam pemerintahannya itu, maka Sultan Agung merumuskan ajaran akulturatif dan integrative dalam masyarakat Mataram yang dirumuskan dalam Serat Sastra Gending.

Setelah mengkaji isi naskah tersebut dan didukung analisis hermeneutika sosial, maka diperoleh kesimpulan: pertama, Serat Sastra Gending berisi pokok pikiran tentang dua macam integrasi yaitu integrasi diri pribadi: berupa keseimbangan unsur jasmaniah dan ruhaniah (pola kepribadian lokal) berupa keseimbangan lahir batin, kejujuran perilaku dan hati, dimana antara jiwa dan raga seirama sebagaimana laras irama langgam sastra dan gending, disitulah timbul kebahagiaan hakiki dan integrasi Ilahi : bahwa Tuhan itu pada hakekatnya beremanasi mewujud pada mahluk (diri manusia) yang terdapat pada inti semua paham agama, dalam Islam disebut konsep waḥdat al-wujûd, dalam Hindu ddisebut konsep manitis Dewa Wisnu dalam diri Sri Kresna dan dalam paham Jawa termaktub dalam caraka. Tidak perlu saling dipertentangkan agar tercapai masyarakat beragama yang seirama, harmonis dan bersatu.

Kedua, Menurut Sultan Agung, manusia hendaknya memahami hakekat ajaran agama secara seimbang, hal itu akan membuat hidup manusia 
harmonis dan damai, tidak saling menyalahkan dan menjatuhkan. Disitulah inti dakwah dengan model penetration pacifique. Hakekat ajaran agama, merupakan konsep pemersatu, yang mampu melahirkan kebahagiaan dalam hidup bermasyarakat.

\section{Daftar Pustaka}

Afifi, A. E. (1989). Filsafat Mistis Ibn al-Arabi, (terj.) Syahrir Mawi dan Nandi Rahman. Gaya Media Pratam.

Ahimsaputra, H. S. (1995). Islam Jawa dan Jawa Islam: Sinkretisasi Agama di Jawa. Seminar Sejarah Dan Depdikbud.

Aji, K. B., \& Ahmad, S. W. (2014). Sejarah Raja-raja Jawa. Araska.

Alexandri, M. B., \& Zahra, F. (2017). Industrial Relationships: Comparison of Spirituality in The Work Place And Effectiveness of Organization Between India With Indonesia. Jurnal AdBispreneur, 2(2).

Asmara, A. (2017). Peran Raja-Raja Jawa Dalam Dunia Sastra Jawa Klasik. Mlangun Jurnal Ilmiah Kebahasaan \& Kesastraan, 14(2).

Bizawie, Z. M. (2002). Perlawanan Kultural Agama Rakyat. Keris.

Daryanto, J. (2014). Gamelan Sekaten Dan Penyebaran Islam Di Jawa. Keteg: Jurnal Pengetahuan, Pemikiran, Dan Kajian Tentang Bunyi., 14(1).

Graaf, H. J. De. (1986). Puncak Kekuasaan Mataram: Politik Ekspansi Sultan Agung. Graffiti Pres.

Ismail, A. (2012). Agama Nelayan. Pustaka Pelajar.

Kausar, Z. (2006). Communal Riots in India: Hindu-Muslim Conflict and Resolution. Journal of Muslim Minority Affairs, 26(3), 353-370. https://doi.org/10.1080/13602000601141323

Khan, S. S., \& Sen, R. (2009). Where Are We Going? Perspective on Hindu-Muslim Relations in India. In Peace Psychology in Asia (pp. 43-64). Springer US. https://doi.org/10.1007/978-1-4419-0143-9_3

Kroeber, K. (1948). Anthropology,. Harcout, Brace and Coompany.

Kurnialoh, N. (2015). Nilai-Nilai Pendidikan Agama Islam dalam Serat Sastra Gendhing. Ibda': Jurnal Kebudayaan Islam, 13(1).

Larasati, D. (2018). Globalisasi Budaya dan Identitas: Pengaruh dan Eksistensi Hallyu (KoreanWave) versus Westernisasi di Indonesia. Jurnal Hubungan Internasional, $X I(1)$.

Lombard, D. (2000). Nusa Jawa Silang Budaya II. Gramedia Pustaka Utama.

Maurice, D. (1985). Sosiologi Politik. CV. Rajawali.

Mawardi, I. (2011). Pemberdayaan Kearifan Lokal Dalam Perspektif Pembangunan Berkelanjutan. JRL, 8(1). 
Miswanto, A. (2012). Pranata Sosial Islam,. P3SI UMM.

Noer, K., \& Azhari, I. A. (1995). Waḥdat al-Wujûd Dalam Perdebatan. Paramadina.

Otta, Y. A. (2015). Dinamisasi Tradisi Islam di Era Globalisasi: Studi atas Tradisi Keagamaan Kampung Jawa Tondano. Sosiologi Reflektif, 10(01).

Palmer, R. E. (1969). Hermeneutics. Northwenstern University Press.

Poerwanto, H. (1999). Asimilasi, Akulturasi, Dan Integrasi Nasional. Humaniora, 11(3).

Purwanto, M. R., Chotimah, C., \& Mustofa, I. (2018). Sultan Agung's Thought of Javanis Islamic Calender and its Implementation for Javanis Moslem. International Journal of Emerging Trends in Social Sciences, 4(1), 9-14. https://doi.org/10.20448/2001.41.9.14

Riyadi, H. (2014). Kesalehan Sosial sebagai Parameter Kesalehan Keberislaman. AnNida': Jurnal Pemikiran Islam, 39(1).

Runes, D. D. (1976). Dictionary of Philosophy. Littlefield.

Saefullah, M. (2018). Nilai-Nilai Pendidikan Agama Islam Pada Tradisi Nyadran Di Desatraji Kecamatan Parakan Kabupaten Temanggung Jawa Tengah. Jurnal Paramurobi, 1(2).

Sangidu, W. (2008). Wujud: Polemik Pemikiran Sufistik Hamzah Fansuri dan Syamsuddi Sumatrani dengan Nuruddin Ar-Raniri. Gama Media.

Sanusi, I. (2017). Globalisasi Melayu: Peluang dan tantangan Membangun Identitas Melayu dalam Konteks Modernitas. Tarbawiyah, Jurnal Ilmiah Pendidikan, 01(01).

Soekanto, S. (2011). Mengenal Tujuh Tokoh Sosiologi. Rajawali Press.

Sokah, U. A. (1994). Din-I-Ilahi: Kontroversi Keberagamaan Sultan Akbar. Ittaqaq press.

Sungaidi, S. (2019). Dakwah: Priyayi dan Santrinisasi. Dakwah: Jurnal Kajian Dakwah Dan Kemasyarakatan, 22(2), 123-136. https://doi.org/10.15408/dakwah.v22i2.12064

Supajar, D. (1988). Kedudukan Laku dalam Rangka Pandangan Hidup Orang Jawa. Yogyakarta Yayasan Ilmu Pengetahuan dan Kebudayaan "Panunggalan" Lembaga Javanologi.

Supajar, D., \& Prihantoro, A. (2001). Filsafat sosial serat sastra gending. Fajar Pustaka Baru.

Taylor, E. B. (1958). The Primitive Culture. Harper and Brothers.

Tim Penyusun. (1988). Ensiklopedi Nasional Indonesia (jilid 2). Cipta Adi Pustaka.

Umikalsum, A., \& Fauzan, F. (2019). Integrasi Sosial Dalam Membangun Keharmonisan Masyarakat. Jawi, 2(1).

Zaenudin, Z. (2014). Ajaran Tasawuf Sultan Agung: Kajian Isi Serat Sastra Gendhing. Penamas, 27(3).

Zakaria, Z. L. S. (2011). Budaya Jakarta: Budaya Metropolitan, Budaya Pop, dan Superkultur. Jurnal Al-Azhar Indonesia Seri Pranata Sosial, 1(2). 